\title{
The burden of suicidal ideation across Europe: a cross-sectional survey in five countries
}

This article was published in the following Dove Press journal:

Neuropsychiatric Disease and Treatment

\author{
Dena $\mathrm{H}$ Jaffe \\ Benoit Rive ${ }^{2}$ \\ Tom R Denee ${ }^{3}$ \\ 'Kantar, Health Division, Tel Aviv, Israel; \\ ${ }^{2}$ Janssen-Cilag S.A., Health Economics \\ Market Access and Reimbursement \\ Statistics, Paris, France; ${ }^{3}$ Janssen-Cilag \\ Limited, Health Economics Market \\ Access and Reimbursement, High \\ Wycombe, UK
}

Background: Suicidal ideation (SI) is an associated risk of depression, affecting $30-40 \%$ of the depressed population. However, there is a paucity of studies investigating the impact of SI in Europe. This retrospective observational study examined the burden of SI among adults with major depressive disorder (MDD) in the 2017 National Health and Wellness Survey in five European countries: France, Germany, Italy, Spain, and the UK.

Methods: Bivariate analyses evaluated group differences between respondents with MDD with and without SI according to demographic characteristics, self-reported health-related quality of life, work productivity and activity impairment (WPAI), and healthcare resource utilization (HRU). Generalized linear models examined group differences country-wise, after controlling for relevant confounders.

Results: Among 52,060 respondents, 3,308 individuals were diagnosed with MDD, comprising SI $(n=905)$ and non-SI $(n S I)(n=2403)$ patients. Adjusted differences (ADs), compared to the general population, were observed using the Medical Outcomes Study Short Form Survey (SF-12v2) mental component summary scores (AD: $\mathrm{SI}=-20.02, \mathrm{nSI}=-10.77$ ), physical component summary scores (AD: $\mathrm{SI}=-4.49$, $\mathrm{nSI}=-2.50$ ), and EuroQoL-5 Dimensions (AD: $\mathrm{SI}=-0.34, \mathrm{nSI}=-0.15$ ) (for all, $p<0.001$ ). Significantly greater WPAI and higher HRU were associated with SI compared to nSI.

Conclusion: The results illustrate the unique impact of SI within the MDD population and the need to reduce the burden.

Keywords: burden, healthcare resource utilization, major depressive disorder, suicidal ideation, work productivity and activity impairment

\section{Introduction}

The societal burden of depression is further complicated by its association with suicidal ideation (SI). ${ }^{1}$ SI is undertreated and carries social stigma, thereby affecting effective screening and management., ${ }^{1,2}$ According to the Diagnostic and Statistical Manual of Mental Disorders, Fifth Edition (DSM-5), major depressive disorder (MDD) is a combination of five or more symptoms, with at least one of the symptoms being depressed mood or anhedonia. ${ }^{3}$ These symptoms must be continuously present for at least 2 weeks; and cause distress and/or functional impairment in employment, social relationships, or other major life domains and social roles. MDD is a severe recurring illness accompanying depressed mood, state of guilt, low self-esteem, loss of interest, poor concentration, troubled sleep or appetite, and risk of suicide. ${ }^{4}$ The Global Burden of Disease Study 2015 identified depressive disorders as the third leading cause of disability, ${ }^{5}$ affecting nearly $4.4 \%$ of world's population ${ }^{6}$ with a global prevalence of $4.7 \% .^{7}$ In the European Union
Correspondence: Dena $\mathrm{H}$ Jaffe Kantar, 4 Ariel Sharon St. Givatayim,

Tel Aviv 53447 Israel

Tel +97253201 5551

Email Dena.Jaffe@kantar.com 
(EU), MDD is the most common psychiatric condition, with a lifetime prevalence of $12.8 \%{ }^{8}$

Approximately $30-40 \%$ of MDD patients experience SI. ${ }^{9}$ A survey of 17 countries estimated SI prevalence in the general population as $9.2 \% .{ }^{10}$ Although there is evidence that SI risk factors may vary slightly by age group, ${ }^{11}$ some of the major risk factors associated with SI are being female, younger, and divorced or widowed. ${ }^{12}$ Pre-existing or coexisting health conditions, such as depressive disorders (major and bipolar), stroke, and cognitive impairment, are also important predictors for suicide, especially among younger adults. ${ }^{12,13}$

There is a strong connection between SI and healthrelated quality of life (HRQoL). A South Korean crosssectional study found that each one-unit increase in HRQoL (as measured by the Euro-QoL-5 Dimensions [EQ-5D] Index score) was associated with $70 \%$ lower odds of SI among psychiatric center outpatients with MDD. ${ }^{14}$ In the PATH survey between 1999 and 2019, an Australian longitudinal study, individuals with SI (vs no SI) had poorer physical and mental HRQoL over the 8 -year study period. ${ }^{15}$ In a US survey with a large cohort, higher levels of SI were associated with significantly lower scores for HRQoL compared with patients reporting no SI. ${ }^{16}$

SI and suicide are also linked to a substantial impairment of work productivity and a high economic burden. Depressive episodes and SI have consistently impacted absenteeism and presenteeism in the working population. ${ }^{17}$ In 2000, the suicide-related cost of $\$ 5.4$ billion and workplace cost (absenteeism and presenteeism) of $\$ 51.5$ billion contributed to $7 \%$ and $62 \%$, respectively, of the increased economic burden of depression ( $\$ 83.1$ billion). ${ }^{18}$ Evidently, absenteeism and presenteeism have increasingly contributed to impairments in work productivity. In the USA, the national cost of fatal and non-fatal suicidal injuries had alone incurred an increased cost of $\$ 58$ billion in 2013, and work productivity losses contributed $97 \%$ to this annual cost. ${ }^{19}$

Screening for MDD has been unequivocally suggested by community preventive services task forces and other institutions to reduce the clinical morbidity attributed to this condition. ${ }^{20}$ Given the well-established link between depression and suicide, implementation of screening in primary care may potentially have the benefit of facilitating diagnosis and treatment for MDD patients, especially those with SI. Such an approach would be particularly timely in the European region, with six European nations ranking among the top 20 for highest rates of suicide globally. ${ }^{21}$ However, there are few studies that have investigated the multifaceted burden attributed to SI in the European region, and greater clarification on this important issue is warranted. In high-income countries (France, Germany, Italy, Spain, and the UK), suicidal mortality rates are still medium to high ${ }^{22}$ with more than $90 \%$ of cases having MDD. ${ }^{10}$ We hypothesize that in Europe there is an additional burden to patients with depression associated with SI, which, if identified, could be used to promote and establish improved disease prevention and management. The aim of the current study was to examine the health and economic burden of SI severity among adults with MDD in five countries in Europe: France, Germany, Italy, Spain, and the UK.

\section{Methods}

\section{Data source}

This retrospective observational study was based on subjects enrolled in the National Health and Wellness Survey (NHWS) 2017, which was conducted in five European countries: France, Germany, Italy, Spain, and the UK. The NHWS is s self-administered general health survey of the adult population (aged $\geq 18$ years) administered via the Internet and designed to reflect the health of the general population of each country. The study was reviewed and approved by the Pearl Institutional Review Board (Indianapolis, IN, USA). Informed consent was provided by all respondents.

MDD patients were classified based on the following inclusion criteria: 1) self-reported depression in the past 12 months, 2) self-reported physician diagnosis for depression (ever), and 3) self-reported current use of one or more medication for depression (i.e., monoamine oxidase inhibitor [MAOI], reversible inhibitor of monoamine oxidase A [RIMA]; melatonin receptor agonist [MRA]; norepinephrine-dopamine reuptake inhibitor [NDRI], norepinephrine reuptake inhibitor [NRI], selective serotonin reuptake inhibitor [SSRI], serotonin-norepinephrine reuptake inhibitor [SNRI], serotonin antagonist and reuptake inhibitor [SARI], noradrenergic and specific serotonergic antidepressant [NaSSA]; and/or tricyclic antidepressant [TCA], tetracyclic antidepressant [TeCA]). Patients were excluded if they had a self-reported physician diagnosis of (coexisting) bipolar disease or schizophrenia or a positive screen on the Mood Disorder Questionnaire, or were currently using a monotherapy (ie, an anticonvulsant, atypical or typical antipsychotic, benzodiazepine, lithium, or a tryptophan). ${ }^{23}$ Patients with SI were identified as having moderately severe to severe depressive symptoms based 
on the nine-item validated scale using a 2-week recall period Patient Health Questionnaire (PHQ-9) and a score of 15 or higher. ${ }^{24}$ Kroenke et $\mathrm{al}^{24}$ showed that scores $\geq 15$ had a high specificity and positive predictive value, and "signify the presence of major depression". A score of 2 or more on the PHQ-9 question: "Over the past 2 weeks, how often have you been bothered by thoughts that you would be better off dead or of hurting yourself in some way?" ("Not at all" $=0$; "Several days" $=1$; "More than half of the days"=2; "Nearly every day"=3) was used to classify respondents as having no, low, moderate, or high SI, respectively, with non-SI (nSI) patients identified as all the MDD patients who were not in the SI subset (Figure S1).

\section{Demographics and health characteristics}

Demographic variables included age, gender, marital status (married/living with a partner vs not married), education (university degree vs less), and annual household income (low $<20,000 €$ or $£$, medium $\geq 20,000$ and $<40,000 €$ or $£$, high $40,000+€$ or $£$, or declined to answer). NHWS respondents provided data on body mass index (BMI), smoking status, alcohol use, and exercise behavior for health characteristics. Information was collected according to country of residence.

\section{Depression-specific characteristics}

Depression-specific variables for examination included family history of depression (yes or no), length of diagnosis (calculated by year of diagnosis, relative to year of the survey; <1 year vs $1-3$ years vs $3-5$ years vs $>5$ years), participation in talking therapy (yes or no), anxiety, SI, and current classes of MDD medications.

\section{Comorbidities}

The Charlson Comorbidity Index (CCI) was used to measure the burden of comorbidities. ${ }^{25}$ Specific physical comorbidities were also assessed, including a self-reported diagnosis of anemia, arrhythmia, cancer, chronic heart failure, chronic kidney disease, diabetes (type 1 or 2 ), hepatitis (A, B, or C), hypertension, and rheumatoid arthritis.

\section{Health status and HRQoL}

Health status was assessed using the EuroQoL-5 Dimensions, 5-level (EQ-5D-5L) questionnaire examining mobility, self-care, usual activities, pain/discomfort, and anxiety/depression, with levels representing an increasing degree of severity of health status. ${ }^{26,27}$ Descriptive scores were converted into a single index value according to country-specific value sets. The EuroQol visual analogue scale (EQ-VAS) is a single measure of self-rated health, with the endpoints being "Best imaginable health state" and "Worst imaginable health state".

HRQoL was measured by the Medical Outcomes Study 12-item Short Form Survey version 2 (SF-12v2). ${ }^{28,29}$ The instrument is designed to report on eight health domains (physical functioning, physical role limitations, bodily pain, general health, vitality, social functioning, emotional role limitations, and mental health). Two summary scores were calculated, the physical component summary (PCS) and mental component summary (MCS), each normalized to a mean of 50 and an SD of 10 for the general population of the USA. Higher scores indicate better health status. In addition, the six-dimensional health state short form (SF6D) based on the SF-12v2 was used as a preference-based health utility (calibrated between $0=$ death and $1=$ perfect health).

\section{Work productivity and activity impairment}

The Work Productivity and Activity Impairment (WPAI) questionnaire was used to assess work productivity loss among employed respondents and activity impairment among all respondents in the past week, as presenteeism (reduced productivity while at work), absenteeism (time absent from work), overall work productivity impairment (a combination of presenteeism and absenteeism), and activity impairment. ${ }^{30}$ WPAI scores represent the percentage of time impaired in the past week.

\section{Healthcare resource utilization (HRU)}

The number of each type of HRU event (healthcare professional [HCP] visits, emergency room [ER] visits, hospitalizations, other types of visits, psychiatrist visits, and psychologist/therapist visits) was provided by the participants. A binary response was created to represent the percentage who reported one or more event versus those who reported no resource utilization, for each type of event.

\section{Statistical analysis}

Means and SDs (continuous variables) and frequencies and percentages (categorical variables) were reported for all study variables separately by country. Bivariate analyses were performed to evaluate differences between 
respondents with MDD by level of SI severity in demographic characteristics, comorbidities, self-reported HRQoL, WPAI, and HRU. Chi-squared tests were used to examine differences between groups on categorical variables, with ANOVA tests to evaluate group differences on continuous variables.

Generalized linear models (GLMs) were used to examine group differences, controlling for relevant confounds, separately by country. All models were adjusted for sociodemographic (gender, age, country, marital status, education, household income, employment status) and health status (BMI, exercise, alcohol use, smoking status, CCI) variables. For the GLMs, a normal distribution with an identity function and a negative binomial distribution with a log-link function were specified for normally distributed and positively skewed outcome variables, respectively. The $p$-values $<0.05$ (two-tailed) were considered to be statistically significant for the multivariable analyses. Adjusted differences (ADs), relative risks (RRs), or odds ratios (ORs) and 95\% CIs for SI and nSI patients versus the general population were calculated, as well as estimated marginal means and $95 \%$ CIs for each group on all outcomes.

\section{Results}

\section{Demographic and clinical characteristics}

The present study, with a total of 52,060 respondents, identified adult patients diagnosed with MDD ( $\mathrm{n}=3,308)$, comprising SI $(\mathrm{n}=905)$ and $\mathrm{nSI}(\mathrm{n}=2,403)$ patients, compared to healthy controls $(\mathrm{n}=48,752)$. Symptoms of MDD were reported across Europe (France, $n=513$; Germany, $n=824$; Italy, $n=287$; Spain, $\mathrm{n}=264$; and UK, $\mathrm{n}=1,420$ ). The baseline demographic and clinical characteristics among SI, nSI, and general population groups are shown in Table 1. The MDD population (with SI or nSI) was less likely to have a university education, be employed, or be married/living with a partner compared to the healthy group. Those in the MDD population were more likely to be obese, smokers, with high alcohol intake, and with a predominantly less active lifestyle and higher CCI than the healthy respondents. Within the MDD population, the SI group had a significantly higher incidence of anemia $(p=0.002)$, rheumatoid arthritis $(p \leq 0.001)$, and HIV/AIDS $(p=0.007)$ than the nSI group. Compared to the general population, hypertension, diabetes, anemia, rheumatoid arthritis, chronic kidney disease, and chronic heart failure were more prevalent in SI and nSI patients (all $p \leq 0.001$ ).

\section{Depression-related characteristics}

Depression-related characteristics were comparable among SI and nSI respondents for family history of depression, and use of depression medication, such as TeCA/TCA, and potential augmentation/combination medications such as benzodiazepine, antipsychotics, NDRI/NRI, and MAOI/ RIMA (Table 2). However, compared to nSI, SI patients more frequently reported participation in talking therapy $(p \leq 0.001)$. Between $82 \%$ and $84 \%$ of adult patients with MDD who had a PHQ-9 $\geq 15$ across countries had some degree of SI, and $57 \%$ reported moderate to severe SI (range 45-65\%) (Figure 1).

\section{HRQoL}

The absolute differences for HRQoL among SI and nSI respondents compared to general population controls were obtained after adjusting for demographics and health characteristics (Table 3). Both the SI and nSI groups had significantly poorer health status compared to the general population (EQ-5D Index, -0.34 and -0.15 for SI and nSI, respectively, both $p \leq 0.001$ vs general population). SI patients reported significantly lower scores than the general population in MCS (-20.02), PCS (-4.49), EQ-VAS (-29.44), and all the components of the SF-12, including for bodily pain $(-8.70)$, general health $(-11.00)$, mental health $(-17.40)$, physical functioning $(-6.68)$, emotional role functioning $(-18.94)$, physical role functioning $(-9.74)$, social functioning $(-16.20)$, and vitality $(-11.68)$ (all $p \leq 0.001$ ), implying lower HRQoL compared to general population respondents. The findings showed a similar trend in HRQoL across countries (Table S1).

\section{WPAI}

Higher absenteeism (RR: 5.06; 95\% CI 4.56 to 5.63), presenteeism (RR: 2.67; 95\% CI 2.38 to 3.00), work productivity impairment (RR: 2.91; 95\% CI 2.62 to 3.23), and activity impairment (RR: 2.53 ; 95\% CI 2.37 to 2.71) were associated with the SI population compared to the nSI population (Figure 2A), with a considerably higher relative risk than the general population. WPAI scores were similar across Europe for SI patients compared to nSI patients, except for absenteeism, which was observed to be higher in France, Germany, and the UK. Compared to the general population, SI in all five European countries resulted in comparable work productivity loss and activity impairment (Table S2). 
Table I Demographic and clinical characteristics among SI, nSI, and general population groups ${ }^{\mathrm{a}}$

\begin{tabular}{|c|c|c|c|c|c|c|c|c|c|}
\hline & \multicolumn{2}{|c|}{$\begin{array}{l}\text { (a) SI } \\
(n=905)\end{array}$} & \multicolumn{2}{|c|}{$\begin{array}{l}\text { (b) } n S I \\
(n=2,403)\end{array}$} & \multicolumn{2}{|c|}{$\begin{array}{l}\text { (c) General } \\
\text { population } \\
(n=48,752)\end{array}$} & \multicolumn{3}{|c|}{$p$-value } \\
\hline & $\%$ & $\mathbf{n}$ & $\%$ & $\mathbf{n}$ & $\%$ & $\mathbf{n}$ & $a$ vs $b$ & a vs c & b vs c \\
\hline \multicolumn{10}{|l|}{ Gender } \\
\hline Male & 32.0 & 290 & 35.5 & 852 & 47.4 & 23,095 & 0.066 & $<0.001$ & $<0.001$ \\
\hline Female & 68.0 & 615 & 64.5 & $|55|$ & 52.6 & 25,657 & & & \\
\hline \multicolumn{10}{|l|}{ Age (years) } \\
\hline $18-29$ & 17.1 & 155 & 12.7 & 304 & 16.7 & 8,140 & $<0.001$ & $<0.001$ & $<0.001$ \\
\hline $30-39$ & 14.9 & 135 & 13.9 & 334 & 15.7 & 7,652 & & & \\
\hline $40-49$ & 28.1 & 254 & 21.7 & 521 & 17.3 & 8,449 & & & \\
\hline $50-59$ & 25.3 & 229 & 25.7 & 617 & 16.3 & 7,926 & & & \\
\hline$\geq 60$ & 14.6 & 132 & 26.1 & 627 & 34.0 & 16,585 & & & \\
\hline \multicolumn{10}{|l|}{ Country } \\
\hline France & 15.2 & 138 & 15.6 & 375 & 26.5 & 12,910 & 0.024 & $<0.001$ & $<0.001$ \\
\hline Germany & 22.9 & 207 & 25.7 & 617 & 24.1 & $1 \mathrm{I}, 728$ & & & \\
\hline Italy & 46.7 & 423 & 41.5 & 997 & 20.8 & 10,153 & & & \\
\hline Spain & 6.9 & 62 & 9.4 & 225 & 17.3 & 8,410 & & & \\
\hline UK & 8.3 & 75 & 7.9 & 189 & 11.4 & 5,551 & & & \\
\hline Marital status (married or living with partner) ${ }^{\mathrm{b}}$ & 47.2 & 427 & 52.0 & 1249 & 62.7 & 30,561 & 0.025 & $<0.001$ & $<0.001$ \\
\hline Education (completed university) ${ }^{c}$ & 26.1 & 236 & 29.3 & 704 & 38.3 & 18,673 & 0.040 & $<0.001$ & $<0.001$ \\
\hline Household income & & & & & & & 0.043 & $<0.001$ & $<0.001$ \\
\hline Low $(<20,000 €$ or $€)$ & 40.7 & 368 & 36.1 & 868 & 23.1 & 11,257 & & & \\
\hline Medium $(\geq 20,000$ to $<40,000 €$ or $€)$ & 33.0 & 299 & 33.7 & 810 & 37.5 & $|8,28|$ & & & \\
\hline High $(\geq 40,000 €$ or $€)$ & 20.1 & 182 & 22.0 & 529 & 29.1 & 14,180 & & & \\
\hline Declined to answer & 6.2 & 56 & 8.2 & 196 & 10.3 & 5,034 & & & \\
\hline Employed & 44.8 & 405 & 48.8 & 1173 & 55.3 & 26,951 & & & \\
\hline $\mathrm{CCl}$ (mean, SD) & 0.72 & 1.22 & 0.56 & 1.02 & 0.29 & 0.77 & 0.037 & $<0.001$ & $<0.001$ \\
\hline BMI & & & & & & & 0.018 & $<0.001$ & $<0.001$ \\
\hline Underweight $\left(<18.5 \mathrm{~kg} / \mathrm{m}^{2}\right)$ & 4.4 & 40 & 3.1 & 75 & 3.3 & 1,617 & 0.001 & $<0.001$ & $<0.001$ \\
\hline Normal weight $\left(\geq 18.5\right.$ to $\left.<25.0 \mathrm{~kg} / \mathrm{m}^{2}\right)$ & 27.8 & 252 & 31.4 & 754 & 43.7 & 21,328 & & & \\
\hline Overweight $\left(\geq 25.0\right.$ to $\left.<30.0 \mathrm{~kg} / \mathrm{m}^{2}\right)$ & 27.6 & 250 & 30.3 & 728 & 31.4 & 15,293 & & & \\
\hline Obese $\left(\geq 30.0 \mathrm{~kg} / \mathrm{m}^{2}\right)$ & 30.1 & 272 & 26.0 & 625 & 14.9 & 7,243 & & & \\
\hline Declined to answer & 10.1 & 91 & 9.2 & 221 & 6.7 & 3,271 & & & \\
\hline Exercised & 41.5 & 376 & 51.6 & 1239 & 62.2 & 30,342 & $<0.001$ & $<0.001$ & $<0.001$ \\
\hline Alcohol use (daily) & 6.3 & 57 & 5.5 & 132 & 8.0 & 3,881 & 0.102 & $<0.001$ & $<0.001$ \\
\hline Current smoker & 36.7 & 332 & 30.3 & 728 & 22.4 & 10,900 & 0.714 & $<0.001$ & $<0.001$ \\
\hline \multicolumn{10}{|l|}{ Comorbidities } \\
\hline Hypertension & 27.0 & 244 & 26.7 & 641 & 19.1 & 39,450 & 0.868 & $<0.001$ & $<0.001$ \\
\hline Diabetes (type I or 2) & 12.4 & 112 & 11.7 & 281 & 7.3 & 3,579 & 0.589 & $<0.001$ & $<0.001$ \\
\hline Anemia & 9.1 & 82 & 6.0 & 144 & 2.5 & 1,202 & 0.002 & $<0.001$ & $<0.001$ \\
\hline Rheumatoid arthritis & 7.8 & 71 & 4.5 & 107 & 2.2 & 1,050 & $<0.001$ & $<0.001$ & $<0.001$ \\
\hline Cancer & 5.7 & 52 & 6.6 & 158 & 5.2 & 2,552 & 0.383 & 0.494 & 0.004 \\
\hline Arrhythmia & 2.9 & 26 & 3.5 & 84 & 2.3 & $\mathrm{I}, 107$ & 0.373 & 0.229 & $<0.001$ \\
\hline Chronic kidney disease & 1.8 & 16 & 1.2 & 29 & 0.7 & 347 & 0.214 & $<0.001$ & 0.006 \\
\hline
\end{tabular}

(Continued) 
Table I (Continued).

\begin{tabular}{|c|c|c|c|c|c|c|c|c|c|}
\hline & \multicolumn{2}{|c|}{$\begin{array}{l}\text { (a) SI } \\
(n=905)\end{array}$} & \multicolumn{2}{|c|}{$\begin{array}{l}\text { (b) } n S I \\
(n=2,403)\end{array}$} & \multicolumn{2}{|c|}{$\begin{array}{l}\text { (c) General } \\
\text { population } \\
(n=48,752)\end{array}$} & \multicolumn{3}{|c|}{$p$-value } \\
\hline & $\%$ & $\mathbf{n}$ & $\%$ & $\mathbf{n}$ & $\%$ & $\mathbf{n}$ & $a$ vs $b$ & a vs c & b vs c \\
\hline Hepatitis A & I.I & 10 & 1.0 & 24 & 0.9 & 421 & 0.787 & 0.438 & 0.486 \\
\hline HIVIAIDS & 0.8 & 7 & 0.2 & 4 & 0.2 & 100 & 0.007 & $<0.001$ & 0.681 \\
\hline
\end{tabular}

Notes: ${ }^{a}$ Data are shown as \% and $\mathrm{n}$, except for $\mathrm{CCl}$ values (mean, SD); ${ }^{\mathrm{b}}<0.3 \%$ had missing values; ${ }^{\mathrm{c}}$ approximately I\% declined to answer.

Abbreviations: BMI, body mass index; $\mathrm{CCl}$, Charlson Comorbidity Index; nSI, non-suicidal ideation; SI, suicidal ideation.

Table 2 Depression-related characteristics among respondents with SI or nSI

\begin{tabular}{|c|c|c|c|c|c|}
\hline & \multicolumn{2}{|c|}{ SI $(n=905)$} & \multicolumn{2}{|c|}{$n S I(n=2403)$} & \multirow[t]{2}{*}{$p$-value } \\
\hline & $\%$ & $\mathbf{n}$ & $\%$ & $\mathbf{n}$ & \\
\hline Family history of depression & 44.1 & 399 & 38.5 & 924 & 0.003 \\
\hline Length of diagnosis & & & & & 0.266 \\
\hline$<1$ year & 4.7 & 41 & 6.1 & 139 & \\
\hline $\mathrm{I}-3$ years & 16.3 & 143 & 17.7 & 403 & \\
\hline $3-5$ years & 10.3 & 91 & 10.3 & 234 & \\
\hline$\geq 5$ years & 68.8 & 605 & 65.9 & I,497 & \\
\hline Participation in talking therapy & 30.6 & 277 & 22.7 & 546 & $<0.001$ \\
\hline \multicolumn{6}{|c|}{ Prescription medication use for depression } \\
\hline SSRI/SNRI/SARI/NaSSA & 90.2 & 816 & 90.6 & 2,177 & 0.708 \\
\hline TeCA/TCA & 13.4 & 121 & 11.5 & 276 & 0.137 \\
\hline Benzodiazepine & 3.9 & 35 & 2.8 & 67 & 0.109 \\
\hline Antipsychotic & 2.7 & 24 & 2.2 & 52 & 0.404 \\
\hline NDRI/NRI & 1.3 & 12 & 1.3 & 31 & 0.935 \\
\hline MAOI/RIMA & 0.4 & 4 & 0.1 & 3 & $-^{\mathrm{a}}$ \\
\hline Lithium & 0.2 & I & 0.3 & 3 & $-{ }^{\mathrm{a}}$ \\
\hline
\end{tabular}

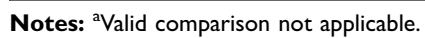

Abbreviations: MAOI, monoamine oxidase inhibitor; NaSSA, noradrenergic and specific serotonergic antidepressant; NDRI, norepinephrine-dopamine reuptake inhibitor; $\mathrm{NRI}$, norepinephrine reuptake inhibitor; nSI, non-suicidal ideation; RIMA, reversible inhibitor of monoamine oxidase A; SI, suicidal ideation; SNRI, serotonin-norepinephrine reuptake inhibitor; SSRI, selective serotonin reuptake inhibitor; TCA, tricyclic antidepressant; TeCA, tetracyclic antidepressant.

\section{HRU}

SI patients had higher numbers of HCP visits (RR: $7.84 ; 95 \% \mathrm{CI}$ 5.34 to 11.51 ), general/family practitioner visits (RR: $3.88 ; 95 \%$ CI 3.20 to 4.70 ), hospitalizations (RR: 2.48 ; $95 \%$ CI 2.06 to 2.99), and ER visits (RR: 2.38; 95\% CI 2.01 to 2.82 ) compared to $\mathrm{nSI}$ patients (Figure 2B). HRU for the SI and nSI population was higher compared to the general population. The SI population was associated with generally higher HRU than nSI across all five European countries, with statistically significant differences between the SI or nSI populations compared to the general population for each HRU outcome (Table S3).

\section{Discussion}

The current multinational study reports the burden of SI by assessing the health and healthcare resource burden across five European countries. Upon comparing SI patients to nSI and general population controls (without a diagnosis of depression), SI was found to be associated with severe depressive symptoms. Furthermore, SI has significant impacts on health status, quality of life, productivity impairment, and HRU.

In the present study, poorer health behaviors and health status, compounded by comorbidities including hypertension, diabetes, anemia, rheumatoid arthritis, chronic kidney disease, and HIV/AIDS, were much more prevalent in the MDD population than in generally healthy respondents. Furthermore, rheumatoid arthritis was more prevalent for SI than for nSI patients within the MDD population. Prior studies have reported similar observations on the association of SI with clinical characteristics such as comorbidities, ${ }^{31-33}$ obesity, ${ }^{34}$ smoking, ${ }^{35}$ and alcohol status. ${ }^{36}$ 


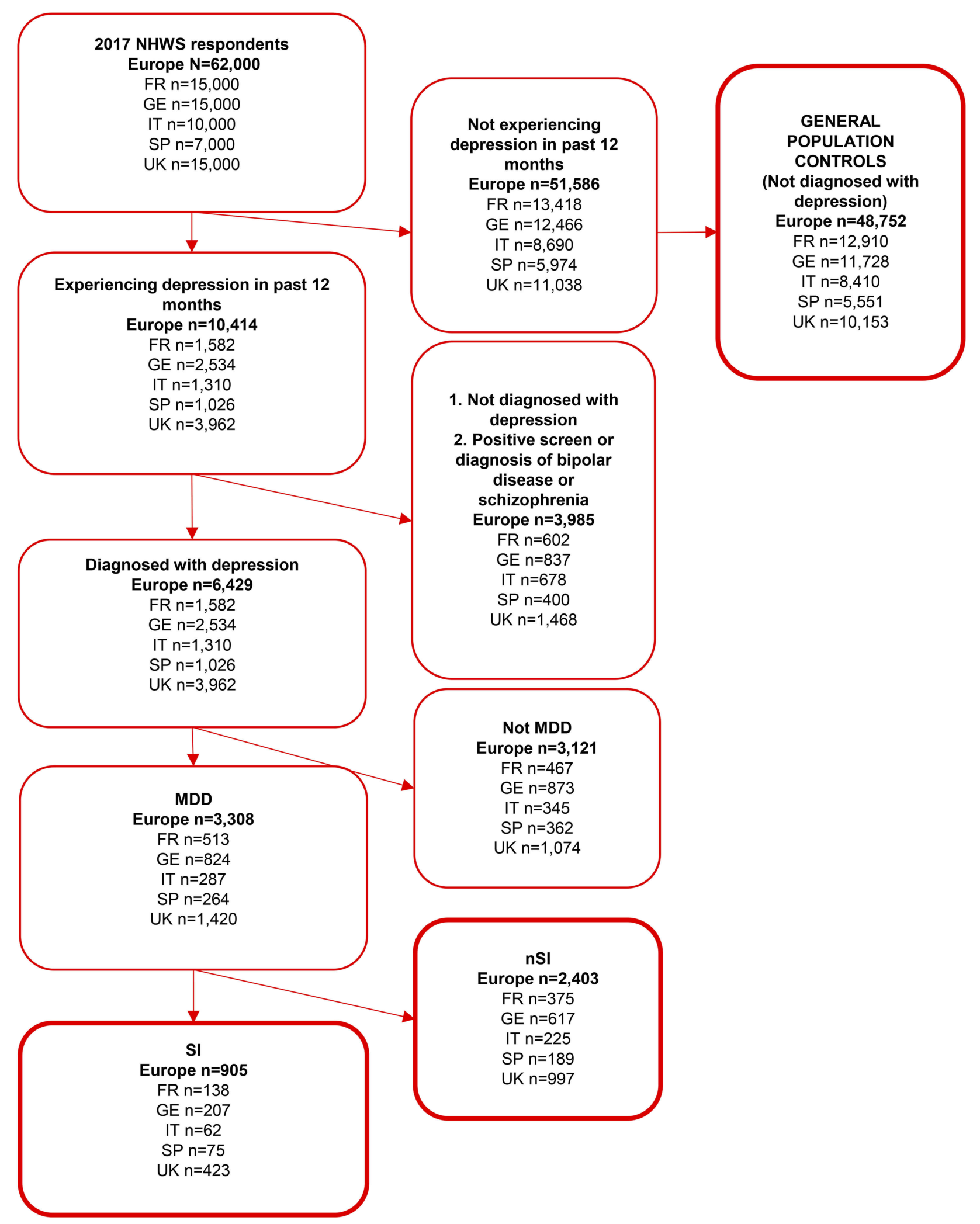

Figure I Study flowchart: cohort identification.

Abbreviations: MDD, major depressive disorder; NHWS, National Health and Wellness Survey; nSI, non-suicidal ideation; SI, suicidal ideation; FR, France; GE, Germany; IT, Italy; SP, Spain. 
Table 3 Adjusted differences for health-related quality of life among respondents with SI or nSI compared to general population controls

\begin{tabular}{|l|l|l|}
\hline \multirow{2}{*}{} & \multicolumn{2}{|l|}{ General population controls versus } \\
\cline { 2 - 3 } & $\mathbf{S I}^{\mathbf{a}}$ & nSI $^{\mathbf{a}}$ \\
\cline { 2 - 3 } & Adjusted difference (LCL to UCL) & Adjusted difference (LCL to UCL) \\
\hline EQ-5D Index & $-0.34(-0.35$ to -0.33$)$ & $-0.15(-0.16$ to -0.14$)$ \\
Health status, EQ-VAS & $-29.44(-30.73$ to -28.16$)$ & $-14.75(-15.56$ to -13.95$)$ \\
MCS & $-20.02(-20.57$ to -19.47$)$ & $-10.77(-11.12$ to -10.43$)$ \\
PCS & $-4.49(-5.00$ to -3.98$)$ & $-2.50(-2.82$ to -2.18$)$ \\
SF-12 Bodily Pain & $-8.70(-9.30$ to -8.08$)$ & $-4.75(-5.13$ to -4.37$)$ \\
SF-12 General Health & $-11.00(-11.50$ to -10.44$)$ & $-6.28(-6.61$ to -5.94$)$ \\
SF-12 Mental Health & $-17.40(-17.95$ to -16.85$)$ & $-9.27(-9.61$ to -8.92$)$ \\
SF-12 Physical Functioning & $-6.68(-7.21$ to -6.15$)$ & $-3.53(-3.87$ to -3.20$)$ \\
SF-12 Role Emotional & $-18.94(-19.60$ to -18.28$)$ & $-10.14(-10.55$ to -9.73$)$ \\
SF-12 Role Physical & $-9.74(-10.30$ to -9.18$)$ & $-5.09(-5.44$ to -4.74$)$ \\
SF-12 Social Functioning & $-16.20(-16.76$ to -15.64$)$ & $-8.45(-8.80$ to -8.10$)$ \\
SF-12 Vitality & $-11.68(-12.26$ to -11.11$)$ & $-6.78(-7.14$ to -6.42$)$ \\
\hline
\end{tabular}

Notes: ${ }^{\mathrm{a}}$ Generalized linear models were adjusted for sociodemographic and health status variables. Comparisons versus the general population were statistically significant at $p \leq 0.001$.

Abbreviations: EQ-5D, EuroQol-5 Dimensions; EQ-VAS, EuroQol visual analogue scale; LCL, lower confidence level; MCS, mental component summary score; nSI, nonsuicidal ideation; PCS, physical component summary score; SF-12, I2-item Short Form Health Survey; SI, suicidal ideation; UCL, upper confidence level.
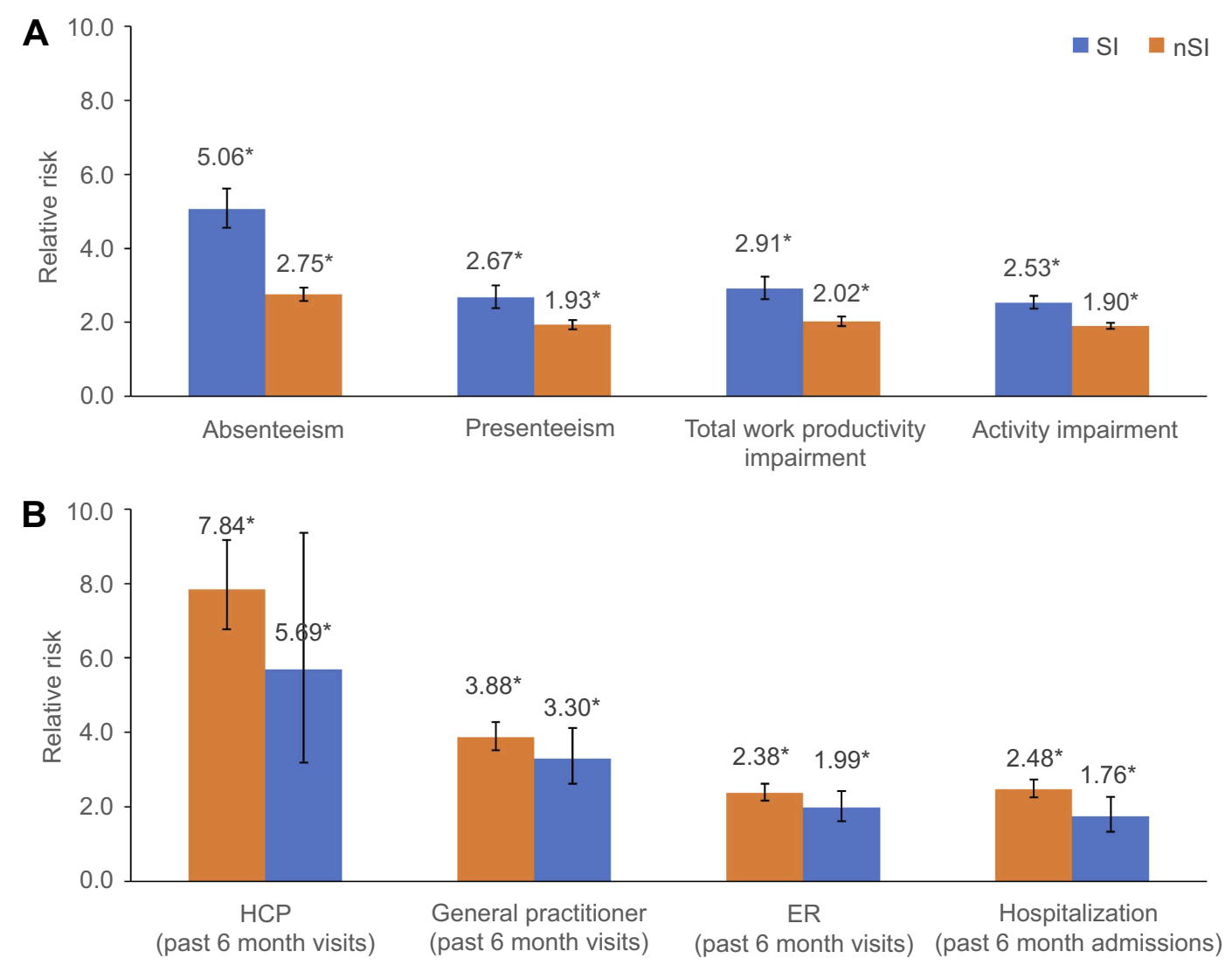

Figure 2 Adjusted risk for (A) WPAI and (B) HRU among respondents with SI or nSI compared to the general population controls. ${ }^{a}$

Note: ${ }^{a}$ Generalized linear models adjusted for socio-demographic and health status variables were used. ${ }^{*} p<0.00 \mathrm{I}$.

Abbreviations: ER, emergency room; HCP, healthcare professional; HRU, healthcare resource use; nSI, non-suicidal ideation; SI, suicidal ideation; WPAI, work productivity and activity impairment. 
After adjusting for demographics and health characteristics, compared to the nSI patients and general population, SI group respondents had significantly lower HRQoL, including EQ-5D Index, EQ-VAS, MCS, PCS, and SF-12 components. A previous cross-sectional study in an elderly population showed similar lowered EQ-5D and EQ-VAS being more prevalent in those with SI $^{37}$ Moreover, cross-sectional and multicenter studies have also shown comparable lower MCS, PCS, and SF-12 scores to be strongly associated with suicidality. ${ }^{14,38,39}$

Work productivity losses were generally found to be higher in SI respondents than in the nSI and general population controls. The relative risk of absenteeism for SI was about 1.8-fold and 5-fold higher compared to the $\mathrm{nSI}$ and general population, respectively. In our study, work-related productivity losses were comparable across Europe. While presenteeism, work productivity impairment, and activity impairment were higher for the SI population, absenteeism was associated with a much greater relative risk for SI than for nSI patients and the general population. Previous studies have reported absenteeism being attributable to depression, similar to our results. It has also been suggested that the persistence of workrelated stress-induced depression may lead to suicidality. ${ }^{17,40}$

SI patients were consistently associated with higher HRU parameters compared to nSI patients and the general population, including the numbers of HCP and family practitioner visits, which were considerably higher compared to the general population. The relative risk associated with HCP visits for SI patients was about 1.4-fold and 7.8-fold higher compared to the nSI and general population, respectively. The relative risk associated with family practitioner visits for SI patients was about 1.2-fold and 3.8-fold higher compared to the nSI and general population, respectively. SI patients showed notable differences in France and Germany for HCP visits and in the UK for family practitioner visits compared to nSI patients and the general population. However, less difference was noticed for hospitalization and ER visits across all the countries between SI, nSI, and the general population.

Although interventions for depression have been explored and typically related to cost-effectiveness, such studies for suicidality are limited. ${ }^{41}$ A prospective cohort study showed that cost and burden were significant for SI patients utilizing emergency department resources. ${ }^{42}$ According to a US retrospective analysis including 39,557 MDD patients, the discontinuation and resumption of antidepressant treatment had incurred the highest healthcare cost. $^{43}$ In the EU region in particular, insufficient funding and unavailability of mental health professionals are considered to be common barriers to accessing mental health services. ${ }^{44,45}$ The gap in care is further illustrated by approximately one-third of the European population experiencing some form of mental disorder, for which only about half of individuals receive treatment. $^{46}$ Currently, pharmacological and nonpharmacological strategies are available to attenuate the physical, cognitive and psychosocial impairments related to major depression. ${ }^{4-50}$ Antidepressants are widely used and include various classes of first- and secondgeneration medications, with varying efficacy and acceptability or treatment discontinuation over time. ${ }^{51}$ Nonpharmacological treatments, such as psychotherapy, repetitive transcranial magnetic stimulation, electroconvulsive treatment, and meditative movements, alone or in conjunction with pharmacological treatments, have been demonstrated as advantageous in the patient's long-term care. ${ }^{48-50,52}$ Investment in care that includes early recognition of this disabling condition can thus reduce the disability and the consequent burden of disease. ${ }^{45}$

\section{Strengths and limitations}

The notable strengths of the study include the relatively large sample size to estimate the burden of disease across several European cities and the survey-specific information available to identify at-risk patients and their burden.

However, the present study also has a few limitations that should be considered when interpreting the results. First, MDD is defined using self-reported data and could not be objectively confirmed via claims data, electronic medical records, or another independent source. Thus, findings may be influenced by any inaccuracies in participants' recall about diagnoses, medications taken, and other study variables. Second, the cross-sectional design of the study precludes the ability to infer causality from the results or to ascertain whether the relationships between study variables change over time. Third, as this was a retrospective study of pre-existing data, only those variables collected in the NHWS were included in the analyses. Therefore, we cannot rule out the possibility that variables not included in the study may be relevant to explaining the observed pattern of findings.

\section{Conclusion}

SI patients had significantly poorer HRQoL, greater work productivity loss and activity impairment, and higher HRU compared to nSI patients and the general population. The 
results illustrate the unique impact that SI has within the MDD population by further affecting HRQoL, work and activity loss, and HRU across Europe. A better, more effective mode of treatment is needed to reduce the economic and humanistic burden experienced by the SI patients.

\section{Acknowledgments}

The authors acknowledge Monolekha Bhattacharya $\mathrm{PhD}$ and Urmila Rao PhD, Indegene Pvt Ltd, for assistance with the literature review and writing.

\section{Author contributions}

All authors contributed to data analysis, drafting or revising the article, gave final approval of the version to be published, and agree to be accountable for all aspects of the work.

\section{Disclosure}

DHJ is an employee of Kantar and TRD and BR are employees of Janssen-Cilag. Kantar received funding from Janssen-Cilag to conduct this study, report on the results, and consult as needed. The authors report no other conflicts of interest in this work.

\section{References}

1. Hardt J, Bernert S, Matschinger H, et al. Suicidality and its relationship with depression, alcohol disorders and childhood experiences of violence: results from the ESEMeD study. $J$ Affect Disord. 2015;175:168-174. doi:10.1016/j.jad.2014.12.044

2. Bernal M, Haro JM, Bernert S, et al. Risk factors for suicidality in Europe: results from the ESEMED study. J Affect Disord. 2007;101 (1-3):27-34. doi:10.1016/j.jad.2006.09.018

3. American Psychiatric Association. Diagnostic and Statistical Manual of Mental Disorders: (5th ed.). Arlington, VA: American Psychiatric Association; 2013.

4. Vietri J, Montgomery W, Otsubo T, Tsuji T, Harada E. Association between pain severity, depression severity, and use of health care services in Japan: results of a nationwide survey. Neuropsychiatr Dis Treat. 2015;11:675-683. doi:10.2147/NDT.S71768

5. Vos T, Allen C, Arora M, et al. Global, regional, and national incidence, prevalence, and years lived with disability for 310 diseases and injuries, 1990-2015: a systematic analysis for the global burden of disease study 2015. Lancet. 2016;388(10053):1545-1602. doi:10.1016/S0140-6736(16)31678-6

6. World Health Organization (WHO). Depression and Other Common Mental Disorders Global Health Estimates. Geneva: World Health Organization; 2017.

7. Ferrari AJ, Somerville AJ, Baxter AJ, et al. Global variation in the prevalence and incidence of major depressive disorder: a systematic review of the epidemiological literature. Psychol Med. 2013;43 (03):471-481. doi:10.1017/S0033291712001511

8. Alonso J, Angermeyer MC, Bernert S, et al. Prevalence of mental disorders in Europe: results from the European Study of the Epidemiology of Mental Disorders (ESEMeD) project. Acta Psychiatr Scand. 2004;109 (s420):21-27. doi:10.1111/j.1600-0047.2004.00325.x
9. Isometsä E. Suicidal behaviour in mood disorders - who, when, and why? Can J Psychiatry. 2014;59(3):120-130. doi:10.1177/0706743714 05900303

10. Nock MK, Borges G, Bromet EJ, et al. Cross-national prevalence and risk factors for suicidal ideation, plans and attempts. Br J Psychiatry. 2008. doi:10.1192/bjp.bp.107.040113

11. Miret M, Caballero FF, Huerta-Ramírez R, et al. Factors associated with suicidal ideation and attempts in Spain for different age groups. Prevalence before and after the onset of the economic crisis. $J$ Affect Disord. 2014;163:1-9. doi:10.1016/j.jad.2014.03.045

12. Miret M, Ayuso-Mateos JL, Sanchez-Moreno J, Vieta E. Depressive disorders and suicide: epidemiology, risk factors, and burden. Neurosci Biobehav Rev. 2013;37(10):2372-2374. doi: 10.1016/j.neubiorev.2013.01.008

13. Pompili M, Venturini P, Lamis DA, et al. Suicide in stroke survivors: epidemiology and prevention. Drugs Aging. 2015;32(1):21-29. doi:10.1007/s40266-014-0233-x

14. Woo JM, Jeon $\mathrm{Hj}$, Noh E, et al.. Importance of remission and residual somatic symptoms in health-related quality of life among outpatients with major depressive disorder: a cross-sectional study. Health Qual Life Outcomes. 2014;12:188. doi:10.1186/s12955-014-0188-y

15. Fairweather-Schmidt AK, Batterham PJ, Butterworth P, Nada-Raja S. The impact of suicidality on health-related quality of life: A latent growth curve analysis of community-based data. J Affect Disord. 2016;203:14-21. doi:10.1016/j.jad.2016.05.067

16. Witt EA, Benson C, Shawi M, et al. Impact of Increasing levels of suicidal ideation among patients with depression impairment. Anxiety and Depression Association of America (ADAA) Annual Conference. San Francisco, CA; 2017.

17. Woo J-M, Postolache TT. The impact of work environment on mood disorders and suicide: evidence and implications. Int J Disabil Hum Dev. 2008;7(2):185-200.

18. Greenberg PE, Kessler RC, Birnbaum HG, et al. The economic burden of depression in the United States: how did it change between 1990 and 2000? J Clin Psychiatry. 2003;64(12):1465-1475.

19. Shepard DS, Gurewich D, Lwin AK, Reed GA, Silverman MM. Suicide and suicidal attempts in the united states: costs and policy implications. Suicide Life-Threatening Behav. 2016;46(3):352-362. doi:10.1111/sltb.12225

20. Siu AL, Bibbins-Domingo K, Grossman DC, et al. Screening for Depression in Adults. Jama. 2016;315(4):380. doi:10.1001/ jama.2015.18392

21. World Bank. Suicide mortality rate (per 100,000 population), 2016. Washington DC; World Bank, 2018.

22. Fond G, Llorca P-M, Boucekine M, et al. Disparities in suicide mortality trends between United States of America and 25 European countries: retrospective analysis of WHO mortality database. Sci Rep. 2016;6:20256. doi:10.1038/srep20256

23. Hirschfeld RMA. The Mood disorder questionnaire: a simple, patient-rated screening instrument for bipolar disorder. Prim Care Companion J Clin Psychiatry. 2002;4(1):9-11.

24. Kroenke K, Spitzer RL, Williams JBW. The PHQ-9: validity of a brief depression severity measure. J Gen Intern Med. 2001;16 (9):606-613. doi:10.1046/j.1525-1497.2001.016009606.x

25. Charlson ME, Pompei P, Ales KL, MacKenzie CR. A new method of classifying prognostic comorbidity in longitudinal studies: development and validation. J Chronic Dis. 1987;40(5):373-383.

26. Brazier JE, Roberts J. The estimation of a preference-based measure of health from the SF-12. Med Care. 2004;42(9):851-859.

27. Ware JEKM. How to Score Version 2 of the SF-12 HEALTH Survey. Lincoln, RI: Quality Metric Incorporated; 2002.

28. Herdman M, Gudex C, Lloyd A, et al. Development and preliminary testing of the new five-level version of EQ-5D (EQ-5D-5L). Qual Life Res. 2011;20(10):1727-1736. doi:10.1007/s11136-011-9903-x

29. van Reenen M, Janssen B. EQ-5D-5L User Guide. Rotterdam: EuroQol Research Foundation; 2015. 
30. Reilly MC, Zbrozek AS, Dukes EM. The validity and reproducibility of a work productivity and activity impairment instrument. Pharmacoeconomics. 1993;4(5):353-365. doi:10.2165/00019053199304050-00006

31. Serafini G, Pompili M, Innamorati M, et al. The impact of anxiety, depression, and suicidality on quality of life and functional status of patients with congestive heart failure and hypertension. Prim Care Companion J Clin Psychiatry. 2010;12(June2005):1-20.

32. Lutz J, Morton K, Turiano NA, Fiske A. Health conditions and passive suicidal ideation in the survey of health, ageing, and retirement in Europe. J Gerontol - Ser B Psychol Sci Soc Sci. 2016;71 (5):936-946. doi:10.1093/geronb/gbw019

33. Steptoe A, Wikman A, Molloy GJ, Kaski J-C. Anaemia and the development of depressive symptoms following acute coronary syndrome: longitudinal clinical observational study. BMJ Open. 2012;2 (1):e000551. doi:10.1136/bmjopen-2011-000551

34. Ju YJ, Han K-T, Lee T-H, Kim W, Park JH, Park E-C. Association between weight control failure and suicidal ideation in overweight and obese adults: a cross-sectional study. BMC Public Health 2016;16(1):259. doi:10.1186/s12889-016-2940-1

35. Poorolajal J, Darvishi N. Smoking and suicide: a meta-analysis. PLoS One. 2016;11(7):e156348. doi:10.1371/journal.pone.0156348

36. Jonas JB, Nangia V, Rietschel M, Paul T, Behere P, Panda-Jonas S. Prevalence of depression, suicidal ideation, alcohol intake and nicotine consumption in rural central India. the central india eye and medical study. PLoS One. 2014;9:11. doi:10.1371/journal.pone.0113550

37. Kwak Y, Kim Y. Health-related quality of life and mental health of elderly by occupational status. Iran J Public Health. 2017;46(8):1028-1037.

38. Saharinen T, Hintikka J, Niskanen L, et al. Health-related quality of life in a population-based sample of men with long-term mental symptoms. Nord J Psychiatry. 2008;62(2):106-112. doi:10.1080/08039480801962921

39. Li H, Luo X, Ke X, et al. Major depressive disorder and suicide risk among adult outpatients at several general hospitals in a Chinese Han population. PLoS One. 2017;12(10):e0186143. doi:10.1371/journal.pone.0186143

40. Cocker F, Nicholson JM, Graves N, Oldenburg B, Palmer AJ. Depression in working adults: comparing the costs and health outcomes of working when ill. PLoS One. 2014;9(9):105430. doi:10.1371/journal.pone.0105430

41. Baj VS, Majo MC, Smit F, van Straten A, Kerkhof AJFM. Reducing suicidal ideation: cost-effectiveness analysis of a randomized controlled trial of unguided web-based self-help. J Med Internet Res. 2012;14(5):e141. doi:10.2196/jmir.1966

42. Ballard ED, Cwik M, Storr CL, Goldstein M, Eaton WW, Wilcox HC. Recent medical service utilization and health conditions associated with a history of suicide attempts. Gen Hosp Psychiatry. 2014;36(4):437-441. doi:10.1016/j.genhosppsych.2014.03.004
43. Gauthier G, Guérin A, Zhdanava M, et al. Treatment patterns, healthcare resource utilization, and costs following first-line antidepressant treatment in major depressive disorder: a retrospective US claims database analysis. BMC Psychiatry. 2017;17(1):222. doi:10.1186/ s12888-017-1489-6

44. Barbato A, Vallarino M, Rapisarda F, Lora A, Caldas De Almeida M. EU-Compase for Action on Mental Health and Well-Being Access to Mental Health Care EUROPE. Utrecht: EU Compass Consortium; 2014.

45. World Health Organization (WHO). Integrating the Prevention, Treatment and Care of Mental Health Conditions and Other Noncommunicable Diseases within Health Systems. WHO European High-Level Conference on Noncommunicable Diseases. Copenhagen, WHO Regional Office for Europe: Ashgabat; 2019.

46. World Health Organization (WHO). WHO Regional Committee for Europe - 63rd Session; Çeşme Izmir: WHO Regional Office for Europe; 2013.

47. Serafini G, Pompili M, Belvederi Murri M, et al. The effects of repetitive transcranial magnetic stimulation on cognitive performance in treatment-resistant depression. A systematic review. Neuropsychobiology. 2015;71(3):125-139. doi:10.1159/000381351

48. Girardi P, Pompili M, Innamorati M, et al. Duloxetine in acute major depression: review of comparisons to placebo and standard antidepressants using dissimilar methods. Hum Psychopharmacol Clin Exp. 2009;24(3):177-190. doi:10.1002/hup.1005

49. Pompili M, Serafini G, Innamorati M, et al. Agomelatine, a novel intriguing antidepressant option enhancing neuroplasticity: A critical review. World J Biol Psychiatry. 2013;14(6):412-431. doi:10.3109/ 15622975.2013 .765593

50. Zou L, Yeung A, Li C, et al. Clinical medicine effects of meditative movements on major depressive disorder: a systematic review and meta-analysis of randomized controlled trials. J Clin Med. 2018. doi: $10.3390 /$ jcm 7080195

51. Cipriani A, Furukawa TA, Salanti G, et al. Comparative efficacy and acceptability of 21 antidepressant drugs for the acute treatment of adults with major depressive disorder: a systematic review and network meta-analysis. Focus (Madison). 2018;16(4):420-429. doi:10.1176/appi.focus.16407

52. Oltedal L, Kessler U, Ersland L, et al. Effects of ECT in treatment of depression: study protocol for a prospective neuroradiological study of acute and longitudinal effects on brain structure and function. BMC Psychiatry. 2015;15:94. doi:10.1186/s12888-015-0477-y 


\section{Supplementary materials}

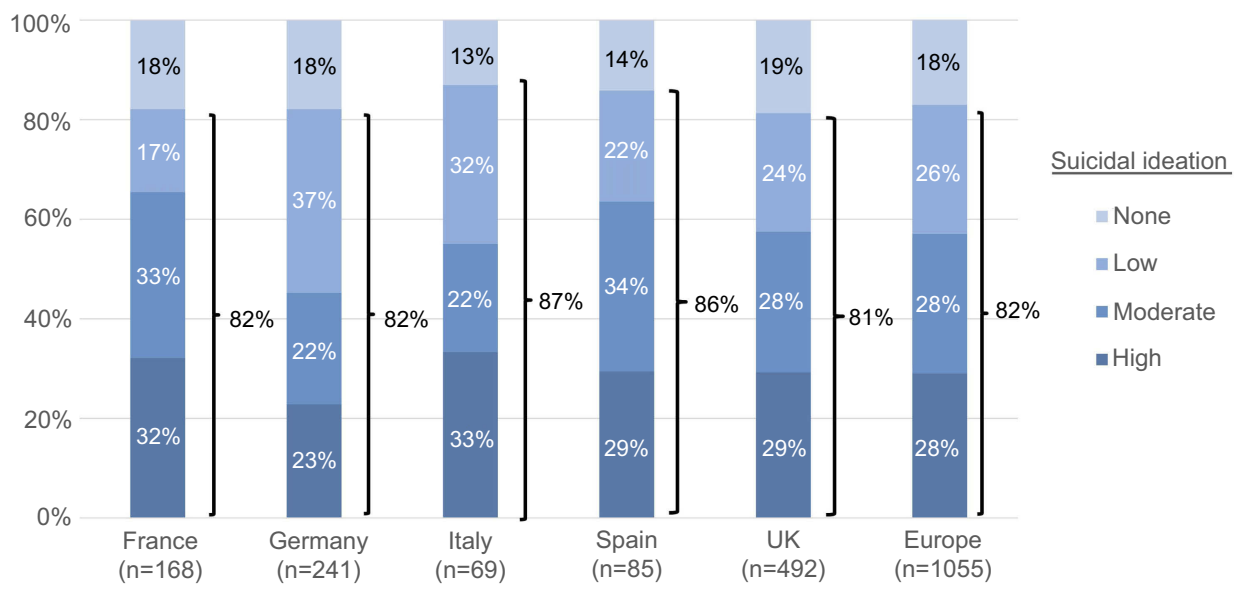

Figure SI Percentage of patients with major depressive disorder at risk for suicidal ideation.

Table SI Adjusted means for health-related quality of life among respondents with SI and nSI compared to general population controls

\begin{tabular}{|c|c|c|c|c|c|c|}
\hline \multirow[t]{2}{*}{ Parameter } & \multicolumn{6}{|c|}{ Adjusted means (SE) ${ }^{a}$} \\
\hline & France & Germany & Italy & Spain & UK & Europe \\
\hline \multicolumn{7}{|l|}{ EQ-5D Index } \\
\hline SI & $0.479(0.017)$ & $0.639(0.011)$ & $0.734(0.013)$ & $0.520(0.018)$ & $0.367(0.011)$ & $0.504(0.006)$ \\
\hline $\mathrm{nSI}$ & $0.601(0.011)$ & $0.768(0.007)$ & $0.813(0.007)$ & $0.738(0.012)$ & $0.599(0.008)$ & $0.691(0.004)$ \\
\hline General population & $0.787(0.004)$ & $0.879(0.003)$ & $0.896(0.003)$ & $0.889(0.004)$ & $0.778(0.004)$ & $0.843(0.002)$ \\
\hline \multicolumn{7}{|l|}{ EQ-VAS } \\
\hline $\mathrm{SI}$ & $50.515(1.718)$ & $46.996(1.357)$ & $48.897(2.359)$ & $44.76 \mathrm{I}(2.303)$ & $42.417(1.036)$ & $45.659(0.666)$ \\
\hline nSI & $60.385(1.073)$ & $59.657(0.853)$ & $63.661(1.278)$ & $62.807(1.518)$ & $58.765(0.734)$ & $60.349(0.432)$ \\
\hline General population & $73.109(0.383)$ & $76.390(0.421)$ & $76.666(0.452)$ & $77.524(0.543)$ & $72.770(0.437)$ & $75.102(0.194)$ \\
\hline \multicolumn{7}{|l|}{ MCS score } \\
\hline SI & $28.961(0.746)$ & $29.714(0.591)$ & $29.255(1.07 I)$ & $33.047(0.946)$ & $27.751(0.430)$ & $28.374(0.287)$ \\
\hline $\mathrm{nSI}$ & $36.384(0.466)$ & $38.815(0.372)$ & $37.705(0.580)$ & $40.501(0.624)$ & $37.981(0.305)$ & $37.625(0.186)$ \\
\hline General population & $46.659(0.166)$ & $50.277(0.183)$ & $46.736(0.205)$ & $49.443(0.223)$ & $49.235(0.182)$ & $48.395(0.084)$ \\
\hline \multicolumn{7}{|l|}{ PCS score } \\
\hline $\mathrm{SI}$ & 47.17I (0.639) & $45.123(0.570)$ & $45.905(0.895)$ & $43.338(0.823)$ & $44.176(0.460)$ & $45.223(0.267)$ \\
\hline $\mathrm{nSI}$ & 47.916 (0.399) & $45.874(0.359)$ & $48.697(0.485)$ & $47.130(0.542)$ & $46.514(0.326)$ & $47.213(0.173)$ \\
\hline General population & $49.563(0.143)$ & $49.145(0.177)$ & $50.592(0.171)$ & $51.288(0.194)$ & $48.389(0.194)$ & $49.711(0.078)$ \\
\hline \multicolumn{7}{|l|}{ SF-12 Bodily Pain } \\
\hline $\mathrm{SI}$ & 40.723 (0.779) & $40.657(0.683)$ & $39.983(1.102)$ & $38.602(1.016)$ & $39.764(0.514)$ & $40.152(0.317)$ \\
\hline nSI & $43.648(0.487)$ & $43.027(0.429)$ & $44.565(0.597)$ & $44.805(0.670)$ & $44.242(0.364)$ & $44.097(0.206)$ \\
\hline General population & $47.802(0.174)$ & $48.863(0.2 \mid 2)$ & $48.864(0.21 \mathrm{I})$ & $51.027(0.240)$ & $48.182(0.217)$ & $48.848(0.092)$ \\
\hline \multicolumn{7}{|l|}{ SF-I2 General Health } \\
\hline SI & $41.419(0.620)$ & $36.974(0.560)$ & $38.398(I .04 I)$ & $37.819(0.894)$ & $37.298(0.483)$ & $37.693(0.277)$ \\
\hline $\mathrm{nSI}$ & $43.777(0.387)$ & $42.219(0.352)$ & $43.112(0.564)$ & $43.268(0.589)$ & $41.840(0.343)$ & $42.392(0.180)$ \\
\hline General population & $48.912(0.138)$ & $48.534(0.174)$ & $48.323(0.199)$ & $49.513(0.211)$ & $48.309(0.204)$ & $48.664(0.081)$ \\
\hline
\end{tabular}

(Continued) 
Table SI (Continued).

\begin{tabular}{|c|c|c|c|c|c|c|}
\hline \multirow[t]{2}{*}{ Parameter } & \multicolumn{6}{|c|}{ Adjusted means (SE) ${ }^{a}$} \\
\hline & France & Germany & Italy & Spain & UK & Europe \\
\hline \multicolumn{7}{|l|}{ SF-I2 Mental Health } \\
\hline $\begin{array}{l}\text { SI } \\
\text { nSI } \\
\text { General population }\end{array}$ & $\begin{array}{l}31.351(0.733) \\
38.475(0.458) \\
48.105(0.164)\end{array}$ & $\begin{array}{l}34.418(0.569) \\
41.848(0.358) \\
50.724(0.177)\end{array}$ & $\begin{array}{l}32.598(1.069) \\
40.660(0.579) \\
48.720(0.205)\end{array}$ & $\begin{array}{l}35.723(0.933) \\
42.307(0.616) \\
50.851(0.220)\end{array}$ & $\begin{array}{l}30.727(0.447) \\
39.720(0.317) \\
49.405(0.189)\end{array}$ & $\begin{array}{l}32.099(0.285) \\
40.232(0.185) \\
49.499(0.083)\end{array}$ \\
\hline $\begin{array}{l}\text { SF-12 Physical Functioning } \\
\text { SI } \\
\text { nSI } \\
\text { General population }\end{array}$ & $\begin{array}{l}45.016(0.680) \\
47.020(0.425) \\
50.184(0.152)\end{array}$ & $\begin{array}{l}45.636(0.563) \\
46.661(0.354) \\
50.940(0.174)\end{array}$ & $\begin{array}{l}44.852(0.947) \\
49.639(0.513) \\
51.789(0.181)\end{array}$ & $\begin{array}{l}43.297(0.893) \\
47.183(0.589) \\
51.895(0.211)\end{array}$ & $\begin{array}{l}41.747(0.475) \\
45.798(0.337) \\
48.964(0.201)\end{array}$ & $\begin{array}{l}44.009(0.277) \\
47.156(0.180) \\
50.689(0.081)\end{array}$ \\
\hline $\begin{array}{l}\text { SF-12 Role Emotional } \\
\text { SI } \\
\text { nSI } \\
\text { General population }\end{array}$ & $\begin{array}{l}30.462(0.868) \\
36.755(0.542) \\
45.834(0.194)\end{array}$ & $\begin{array}{l}27.902(0.688) \\
36.173(0.432) \\
48.497(0.213)\end{array}$ & $\begin{array}{l}29.146(1.232) \\
36.878(0.667) \\
45.586(0.236)\end{array}$ & $\begin{array}{l}30.691(1.144) \\
38.227(0.754) \\
46.971(0.270)\end{array}$ & $\begin{array}{l}27.742(0.539) \\
37.979(0.382) \\
47.759(0.228)\end{array}$ & $\begin{array}{l}27.904(0.34 I) \\
36.700(0.221) \\
46.843(0.099)\end{array}$ \\
\hline $\begin{array}{l}\text { SF-12 Role Physical } \\
\text { SI } \\
\text { nSI } \\
\text { General population }\end{array}$ & $\begin{array}{l}40.630(0.721) \\
43.670(0.450) \\
47.858(0.161)\end{array}$ & $\begin{array}{l}37.732(0.600) \\
41.639(0.377) \\
47.942(0.186)\end{array}$ & $\begin{array}{l}39.969(0.992) \\
43.622(0.537) \\
48.329(0.190)\end{array}$ & $\begin{array}{l}38.812(0.937) \\
43.395(0.618) \\
49.330(0.221)\end{array}$ & $\begin{array}{l}37.897(0.497) \\
43.488(0.352) \\
47.881(0.210)\end{array}$ & $\begin{array}{l}38.418(0.292) \\
43.066(0.190) \\
48.156(0.085)\end{array}$ \\
\hline $\begin{array}{l}\text { SF-I } 2 \text { Social Functioning } \\
\text { SI } \\
\text { nSI } \\
\text { General population }\end{array}$ & $\begin{array}{l}34.422(0.734) \\
39.404(0.459) \\
47.075(0.164)\end{array}$ & $\begin{array}{l}34.119(0.598) \\
40.243(0.376) \\
49.594(0.185)\end{array}$ & $\begin{array}{l}33.335(1.029) \\
40.372(0.557) \\
46.313(0.197)\end{array}$ & $\begin{array}{l}34.549(0.929) \\
41.410(0.613) \\
49.403(0.219)\end{array}$ & $\begin{array}{l}30.876(0.473) \\
40.320(0.335) \\
49.140(0.200)\end{array}$ & $\begin{array}{l}32.030(0.291) \\
39.773(0.188) \\
48.226(0.085)\end{array}$ \\
\hline $\begin{array}{l}\text { SF-I2 Vitality } \\
\text { SI } \\
\text { nSI } \\
\text { General population }\end{array}$ & $\begin{array}{l}38.740(0.753) \\
43.195(0.47 I) \\
48.818(0.168)\end{array}$ & $\begin{array}{l}39.440(0.606) \\
44.904(0.381) \\
52.191(0.188)\end{array}$ & $\begin{array}{l}40.066(1.04 I) \\
45.835(0.564) \\
51.419(0.200)\end{array}$ & $\begin{array}{l}42.76 I(0.98 I) \\
48.235(0.647) \\
54.038(0.23 I)\end{array}$ & $\begin{array}{l}38.651(0.495) \\
42.936(0.351) \\
50.103(0.209)\end{array}$ & $\begin{array}{l}39.524(0.299) \\
44.431(0.194) \\
51.208(0.087)\end{array}$ \\
\hline
\end{tabular}

Notes: ${ }^{a}$ Generalized linear models were adjusted for sociodemographic and health status variables. All comparisons were $p<0.05$ with the exception of the following cases, where $\mathrm{SI}$ and $\mathrm{nSI}$ patients were not statistically different: France, PCS; Germany, PCS and Physical Functioning.

Abbreviations: EQ-5D, EuroQol-5 Dimensions; EQ-VAS, EuroQol visual analogue scale; MCS, mental component summary; nSI, non-suicidal ideation; PCS, physical component summary; SF-12, I2-Item Short Form Health Survey; SI, suicidal ideation. 


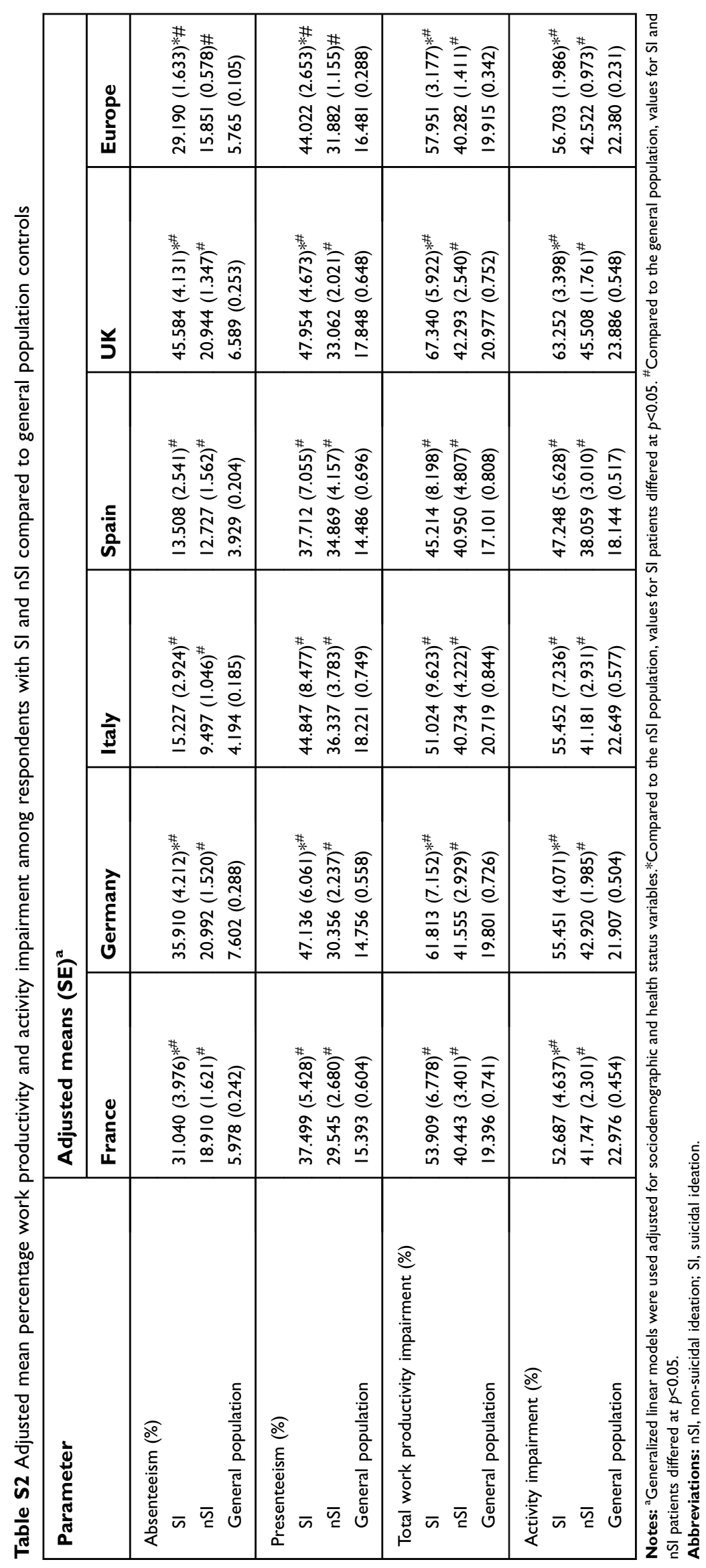


Table S3 Adjusted means for healthcare resource use among respondents with SI and nSI compared to general population controls

\begin{tabular}{|c|c|c|c|c|c|c|}
\hline \multirow[t]{2}{*}{ Parameter } & \multicolumn{6}{|c|}{ Adjusted means (SE) ${ }^{a}$} \\
\hline & France & Germany & Italy & Spain & UK & Europe \\
\hline \multicolumn{7}{|l|}{ HCP visits } \\
\hline SI & $14.524(1.311)^{* \#}$ & $15.338(1.159)^{* \#}$ & $11.517(1.558)^{\#}$ & $14.276(1.753)^{* \#}$ & $7.669(0.443)^{* \#}$ & $12.209(0.445)^{* \#}$ \\
\hline $\mathrm{nSI}$ & $10.013(0.575)^{\#}$ & $10.626(0.514)^{\#}$ & $9.371(0.698)^{\#}$ & $8.175(0.683)^{\#}$ & $5.826(0.246)^{\#}$ & $8.678(0.210)^{\#}$ \\
\hline General population & $4.046(0.088)$ & $4.406(0.110)$ & $4.092(0.114)$ & $3.693(0.116)$ & $2.654(0.069)$ & $3.764(0.043)$ \\
\hline \multicolumn{7}{|l|}{ General/family practitioner } \\
\hline $\mathrm{SI}$ & $3.773(0.373)^{\#}$ & $4.010(0.328)^{* \#}$ & $4.065(0.587)^{* \#}$ & $4.382(0.576)^{* \#}$ & $3.311(0.209)^{* \#}$ & $4.303(0.17 I)^{* \#}$ \\
\hline $\mathrm{nSI}$ & $3.203(0.202)^{\#}$ & $2.732(0.147)^{\#}$ & $2.734(0.226)^{\#}$ & $2.876(0.263)^{\#}$ & $2.480(0.117)^{\#}$ & $3.051(0.082)^{\#}$ \\
\hline General population & $1.658(0.040)$ & $1.609(0.046)$ & $1.814(0.055)$ & $1.472(0.053)$ & $0.988(0.030)$ & $1.504(0.019)$ \\
\hline \multicolumn{7}{|l|}{ Hospitalized } \\
\hline SI & $0.307(0.052)^{\#}$ & $0.227(0.036)^{* \#}$ & $0.224(0.06 \mathrm{I})^{\#}$ & $0.314(0.077)^{\#}$ & $0.257(0.036)^{\#}$ & $0.235(0.019)^{* \#}$ \\
\hline $\mathrm{nSI}$ & $0.206(0.026)^{\#}$ & $0.152(0.018)^{\#}$ & $0.109(0.023)^{\#}$ & $0.195(0.043)^{\#}$ & $0.201(0.022)^{\#}$ & $0.164(0.010)^{\#}$ \\
\hline General population & $0.107(0.006)$ & $0.101(0.007)$ & $0.058(0.006)$ & $0.067(0.007)$ & 0.160 (0.009) & $0.106(0.003)$ \\
\hline \multicolumn{7}{|l|}{ ER visits } \\
\hline SI & $0.331(0.057)^{\#}$ & $0.288(0.043)^{* \#}$ & $0.747(0.149)^{* \#}$ & $1.415(0.220)^{* \#}$ & $0.36 \mathrm{I}(0.04 \mathrm{I})^{\#}$ & $0.463(0.029)^{* \#}$ \\
\hline nSI & $0.230(0.030)^{\#}$ & $0.185(0.021)^{\#}$ & $0.168(0.028)^{\#}$ & $0.728(0.091)^{\#}$ & $0.404(0.033)^{\#}$ & $0.313(0.015)^{\#}$ \\
\hline General population & $0.120(0.007)$ & $0.110(0.008)$ & $0.106(0.008)$ & $0.288(0.017)$ & $0.196(0.010)$ & $0.162(0.004)$ \\
\hline
\end{tabular}

Notes: ${ }^{a}$ Generalized linear models were adjusted for sociodemographic and health status variables. *Compared to the nSI population, values for SI patients differed at $p<0.05$. ${ }^{\#}$ Compared to the general population, values for $\mathrm{SI}$ and $\mathrm{nSI}$ patients differed at $p<0.05$.

Abbreviations: ER, emergency room; HCP, healthcare professional; nSI, non-suicidal ideation; SI, suicidal ideation.

\section{Publish your work in this journal}

Neuropsychiatric Disease and Treatment is an international, peerreviewed journal of clinical therapeutics and pharmacology focusing on concise rapid reporting of clinical or pre-clinical studies on a range of neuropsychiatric and neurological disorders. This journal is indexed on PubMed Central, the 'PsycINFO' database and CAS, and is the official journal of The International Neuropsychiatric Association (INA). The manuscript management system is completely online and includes a very quick and fair peer-review system, which is all easy to use. Visit http://www.dovepress.com/testimonials.php to read real quotes from published authors. 